\title{
Exploring co-creation as a learning process to (re)think public space from a transformative perspective
}

Marluci Menezes (0000-000 I-703 I-0053), National Laboratory for Civil Engineering - LNEC, Lisbon, Portugal. marluci@Inec.pt

Diogo Mateus (0000-000 I-7862-7I 78), Universidade Lusófona, Interdisciplinary Research Centre for Education and Development - CeiED, Lisbon, Portugal. dmateus@ulusofona.pt

\begin{abstract}
This chapter explores the potential of co-creation for the planning of public open spaces that could be more attentive to different, unequal and diverse social ideas, needs and desires. Co-creation is discussed as an innovative opportunity for learning and (re)thinking urban planning. Exploring ideas, literature and experiences (from the European Project C3Places), the chapter discusses the role of co-creation for involving citizens in placemaking. This reflection addresses co-creation as a collective, contextual and engaged process of learning. From this perspective, co-creation is discussed as an open process of learning about predictable ideas in the relationship between socio-spatial imaginary, requirements, needs and urban design procedures from a transformative perspective.
\end{abstract}

Keywords - Sharing knowledge, open creative opportunity, adaptive process, learning process 


\section{INITIAL REMARIS}

The importance that co-creation assumes in urban design, planning and governance is correlated with a growing and influential presence of the digital in the wide range of themes associated with urban and social innovation. More than an ideal of citizens' participation or a passive form of commitment (Voorberg et al.; 20I5; Erjavec, 20I7), co-creation emerges as citizenship in action in placemaking and governance. Hence, citizens are considered co-designers and co-producers, among other possible nuances of the modus operandi with which people are engaged in placemaking. This contributes to endorse the goal of a "networked city"' (Bolier, 2016), whose hybrid meaning can also be associated with the idea of "net localities" (Foth, 20I7), or give rise to a cyberpark ${ }^{2}$. The city emerges as a wider and more complex "platform" than just the fields of communication, sensors (Bollier, 2016) and public administration. However, in the context of placemaking, what can co-creation address?

The term co-creation as a simple substitute for participatory processes may raise doubts. It might even represent itself as another saviour concept, as if it were an (more) effective substitute for everything that has already been developed and experienced about citizen participation and involvement. Voorberg et al. (2015), reflecting on co-creation in the public administration sector, establish the connection between the concept of co-creation and the term of social innovation. For the authors, both terms appear as magical solutions, without actually having a reasoned basis. In the matter of social innovation, they point out that its poor conceptualization probably comes from its widespread use in policy-oriented literature. Therefore, they conceptualise social innovation as a reference to the creation of a long-term response to social needs, especially: "(...) changing the relationships, positions and rules between the involved stakeholders, through an open process of participation, exchange and collaboration with relevant stakeholders, including end-users, thereby crossing organizational boundaries and jurisdictions" (Voorberg et al., 2015: 1334).

Co-creation is thus an inherent condition to the purpose of social innovation, arising from the reference to participation and end-users. Nevertheless, emerging from the private sector, in the business world linked to the development of brands, products and services, the term co-creation comes forth as an opportunity to boost business. Thus, in the private sector, end-users are co-producers of goods or services, seen as those who add value to a given product or service, as well as to a given company, influencing the customer/consumer (Prahalad \& Ramaswamy, 2004). In this context, co-creation relates to "the active involvement of end-users in various

'A "networked city" ideal would involve, among other things: the openness, iteration and experimentation, an emphasis on users and commitment, social equity and inclusiveness (as suggested by Stefaan Verhulst; in Bollier, 2016: 41)

${ }^{2}$ The CyberParks Project (http://cyberparks-project.eu) advocates that the hybrid space is a new type of public space. The insertion of ICTs in physical spaces, however, has to be planned by municipalities with citizens, and not be implemented by private companies and tech suppliers. 
stages of the production process" (Voorberg et al., 20I5: 1335). However, as also pointed out by Voorberg et al. (20I5), in the public sector end-users are citizens.

The purpose of this chapter is therefore to discuss the role of co-creation through citizen involvement in placemaking, starting from ideas, literature and experiences (Project C3Places), by proposing co-creation as an open learning and adaptive process inherent to the placemaking process.

\section{CO-CREATION, END-USERS AND CITIZENS: WHAT ARE THE IMPLICATIONS?}

From a systematic literature review of the terms of co-creation and co-production, Voorberg et al. (2015) point out aspects that need to be recovered in order to better understand the relationship between citizens' involvement in innovation and co-creation in the public sector. Therefore, in the scope of co-creation and/or co-production, citizens are considered key partners in "developing and re-designing public services" (idem: 1347). However, the authors observe a frequent interchange in the use of the terms of co-production and co-creation, without empirically having a clarification that distinguishes them. Nevertheless, given the relationship between public participation, collaborative governance and community involvement, co-creating and co-producing refer to active citizen involvement, as opposed to the passivity with which the idea of participation is associated. The authors warn that greater clarity can come if, in the framework of social innovation, co-creation is differentiated in terms of the degree of citizen involvement (idem: 1347). This contributes to highlight three types of citizen involvement: (i) co-implementer ("involvement in services which refer to the transfer of implementing activities in favour of citizens that have been carried out by government"); (ii) co-designer ("involvement regarding the content and process of service delivery"; (iii) co-initiator ("citizens who take up the initiative to formulate specific services" (Voorberg et al., 2015: 1347).

For Voorberg et al. (2015), co-creation in the public sector refers to citizens engagement as co-initiators or co-designers. As concerns citizen involvement in the co-implementation of public services, the term co-production would be more appropriate. Nevertheless, while co-creation is considered very important in the literature consulted by the authors, the term is practically "a value itself". That is, there are objectives to raise citizen engagement through increased efficiency and effectiveness in order to create more satisfaction. However, the authors do not identify one objective that makes it possible to explain why it is important to co-create and/or co-produce. The analysed texts refer more easily to factors that may influence citizens in co-creation, rather than the results of a co-creation / co-production process. Indeed, the difficulty in detecting a result or product directly resulting from co-creation is transversal to all systematic-critical reflection developed by Voorberg et al. (20I5). 
Returning to the influencing factors, the authors distinguish two sets of factors: those of organisational scope and those linked to the citizens. As for the former, it is understood that they refer to the "compatibility of public organisations to citizen participation". This can be exemplified by the existence of appropriate infrastructure or facilities for communication and training of civil servants and citizens. However, the authors note that administrators and/or politicy-makers do not always act towards citizen involvement, as it can be uncontrollable ("the administrative environment is not aimed at incorporating citizens in public service delivery" (Voorberg et al., 2015: 1347). In terms of factors related to citizens, essentially, they would be associated with citizens' interest in participating, their awareness of the ability and possibility to influence the public sector, and the social capital needed for the development of a sustainable relationship between public sector and citizens. The weak influence of these factors - both on the organisational side and on the citizens' side - is usually associated with "something that the public organization must do" (ibidem: 1348). Voorberg et al. (20I5) also highlight that, regarding the results of co-creation / co-production, two aspects must be retained: (i) the report of specific results would make it possible to ascertain whether the effectiveness of "public service is being enhanced"; (ii) the scant number of studies on specific outcomes confirm that co-creation / co-production is more commonly assumed as a value in itself, "which does not need to be legitimized by referring to external objectives" (ibid: 1348).

From a more operative perspective, in a more recent text, Voorberg et al. (2017: 178) take up the idea of co-creation "as involvement of citizens in the initiation and/or the design of public services to develop beneficial outcomes". Here, citizens are key partners in co-creation initiatives as they have "specific resources and competences which are valuable for (re)designing public service delivery". Through that, transformed into co-creators, citizens are much more than consumers of public services. After consulting the term co-creation in IGI Global, Erjavec (2017: 103) highlights the multitude of ways to explore it while pointing to the affinity of the term for business, marketing and digital technologies. Nonetheless, Erjavec (2017) observes a differentiating aspect about the act of co-creation, which refers to the act of creativity. Thus, co-creation differs from terms such as collaboration and cooperation, although all are taken as actions associated with working, doing, deciding or defining something together. This, in other words, allows us to consider the term co-creation as the possibility of conceiving something new. Citing the Leading Cities report and IGI Global, Erjavec (2017) points out that co-creation differs from public participation, as co-creation techniques allow us to go beyond temporal and spatial boundaries, enabling proactivity and public involvement, with the increment of the decision process. This, on the other hand, would provide new opportunities for self-governance, because it not only involves the community, but also key drivers (stakeholders) in the decision-making process. From the author's point of view, co-creation 
allows us to go a little further than citizen participation, which is considered to be more focused on collaboration between public and decision-makers, and even among influencers (here considered as opinion-makers).

In short, co-creation can be taken as a collective process of value generation. A process in which, starting from the citizens' experience, an innovative interaction is established, and the result reflected in a mutual and continuous process of value creation and, as such, learning and adaptation. This is, then, a generative thinking process that calls for a "creative initiative on the part of the entire team", from researchers, technicians, clients, designers, and the people who will benefit from the co-creative experience ${ }^{3}$ (Sanders \& Stappers, 2018: 9).

\section{CO-CREATION, ICT, CITIZENS AND PUBLIC SPACE: WHAT ARE THE IMPLICATIONS?}

Public participation in urban planning is an essential factor for the success of interventions. Since the public space is understood as collective good, ideally its use would result from a collective desire to have citizen's needs addressed, accessing resources and properly performing activities. However, authorities and technicians created mechanisms that have affected citizen participation in the context of the production of public spaces. In line with the view that the process was very time-consuming and complex, public participation often became a mere public consultation process. This means through a superior decision that is more or less endorsed and thus understood as shared, allowing, as Jacinto (200I: 82) states "to legitimize decisions that are described as representing the expectations of the communities". Participation and legitimation of decisions are often intertwined, along with a conviction that people do not understand most issues raised and, at the same time, are not able to propose technical solutions.

Tackling more directly the placemaking and governance issues, namely from the viewpoint of human-computer interaction, Foth (2017) states that the user of urban space must be rethought on five levels: as resident, as consumer of services, as participant in community consultations, as co-creator in a collaborative approach to placemaking and, finally, from a socio-ecological transitional perspective, "as part of a much larger and more complex ecosystem of more-than-human worlds and of cohabitation - a process that decentres the human in the design of collaborative cities". To Foth (2017: 22) the evolution of the user in his/her relationship with the city and urban governance occurs from the following relations:

- Cities I.0: City Government / Administrator - Citizens / Residents;

- Cities 2.0: City Government / Service Provider - Citizens / Consumers;

- Cities 3.0: City Government / Facilitator - Citizens / Participants;

- Cities 4.0: City Government / Collaborator - Citizens / Co-Creators.

\footnotetext{
${ }^{3}$ Sanders \& Stappers (2018) discuss co-design, considering its purpose to be more directly aimed at the development of design solutions.
} 
Furthermore, Foth (2017) argues that none of the levels of a user's relations is correct or more important than the others; and that "place makers and urban interaction designers" should even take a transdisciplinary and dynamic perspective of these different levels of public space users. However, this perspective does not exclude the conventional approaches to spaces' use and usability, habitually more related to citizens/residents. In this sense, Foth (20I7) refers to studies of ethnographic and sociological nature, even when concerned with the relationship between people, space and digital technologies. According to this author, it is critical that "urban interaction designers" consider: (i) creating "interventions that explored new terrain at the intersection of the physical and digital city"; and (ii) conceiving one "spatial turn" in order to capture digital reality as part of physical reality, that would define a hybrid space (Foth, 20I7: 24) ${ }^{4}$. Regarding consumers, the author refers the interest of urban designers to adopt a more sensitive understanding of the relationship with the customer ${ }^{5}$ and the user. This sensitive understanding of the consumer and client relationship aims to capture the subtle differences "between the ways a client conceives of their user base and the picture emerging from user research the designer conducts"6 (Foth, 2017: 24).

It is interesting to note that Voorberg et al. (2017: 179) refer to the influence of co-creation on the change of "conventional ideas about who is responsible for public service delivery and how decisions are made about the allocation of public resources". In a co-creative dynamic, citizens are different from each other, and play or may play different roles in the course of the process, which contributes to creating different relationships and behaviours. On the one hand, this suggests an interest in learning how to deal with conflicts in the co-creation process. On the other, this brings the benefit of accepting the co-creative process as a mediation context - a process that Foth (2017: 30 ) calls "middle-out". Co-creation is to be understood therefore as a means to mediate interests, needs, knowledge and proposals in order to generate collective benefits. This understanding may also mean overtaking the bipolar meaning of top/down and bottom/up logics. Alternative paths, such as through co-creative perspectives, contribute to the construction of the socio-ecological transition, as requested by Foth (2017). With this objective, it will be interesting to expand and combine socio-spatial experiences, mainly with respect to the relationship between people, their symbolic-cultural ways of interpreting the world, their living spaces and relationship with the territory (Menezes, 20I8).

Co-creation can also be conceived as a "weak utopia" (Cruz, 2016) in the face of the new configuration of urban economy. As Cruz (2016: 48) observes, the distributive economy admits of a "distributed creativity", where big actions are replaced by small

\footnotetext{
${ }^{4}$ About hybrid space, see also: Smaniotto Costa et al. (2017).

${ }^{5}$ The customer is not necessarily only the citizen, but often he/she is the public administration.

${ }^{6}$ For Foth (2017: 24) the challenge for urban designers is "to master a balancing act that requires the artful integration of knowledge and insights about people at different levels of granularity".
} 
and multiple acts. To the author, this shared vision could be a stimulus to think about social innovation, where the driving axis would be co-design. In a shared vision, both of networks and of less rigid systems, digital technologies can play an important mediating role. However, as discussed by Sennet (20I8), it is important to address two fundamental assumptions to understand the role that ICT can play in the framework of a smart city. First, the smart city as a prescriptive postulation implies a closed, appeased, authoritarian city which does not accept frictions and conflicts, diminishing the cognitive capacity of people who fail to reflect and grasp their surroundings, conceived as the territory. Regarding the second assumption, smart city introduces the idea of coordination; the coordinated smart city is open, and technology helps in terms of its coordination. The coordinated smart city gives more control to citizens and provides feedback to them. The coordinated city also enables negotiation, choice and options, being more democratic, inclusive and fair - from a human, social, spatial and environmental point of view. However, it is a perspective that entails efforts and an experience whose "implementation will require a new ethos and (...) a new literacy" (Cruz, 2016: 48).

\section{LEARNING IN CO-CREATION AND SOCIAL LIVING LABS}

A context of excellence for the pursuit of co-creative purposes involves implementing social living labs. According to Nesti (2018: 3/3), the term "living lab" is first referred to at the beginning of the 1990s in an article describing students' experience in a problem-solving process in a neighbourhood in Philadelphia. The term was further developed in 1995 by William J. Mitchel (from MIT - Media Lab and School of Architecture) to test and build up new methodologies that could enable the approach to complex social problems. As a result, living labs have gained popularity in the framework of creating new business innovation models. In 2006, the term was officially taken over by the European Union. ${ }^{7}$

For Nesti (2018), there are three features that define living labs: (i) they are built on the basis of a collaborative organisational approach involving public authorities, companies, research organisations, and people; (ii) they use co-creative and co-design methodologies to seek solutions to social problems, explore uses and emerging behaviours, as well as prototypes in real contexts, and assess the impact caused; (iii) they are presented as an open concept for innovation, considered to be possible from "a continuous process of exchange of knowledge between actors and learning-by-doing” (Nesti, 20I8: 3I4).

Learning to work in the open sense which the co-creative process, in principle, presents in the framework of the also much-needed innovation in urban planning, is fundamental for a transformative transition of urban spaces. Conceiving co-creation

\footnotetext{
“(...) when the Finnish Presidency launched the European Network of Living Labs (ENOLL) and the European Commission began financing the creation of LLs under the $7^{\text {th }}$ Framework Programme for Research and Development as part of the smart city strategy promoted across the EU (...)" (Nesti, 2018: 313).
} 
as a methodology that seeks to create jointly a sensitive layer of complementary guidelines for programmes and projects brings about the issue of learning as an inherent part of the whole co-creation process.

Co-creation processes generate, at the same time, an open learning opportunity, because in a collaborative and interactive process different ideas can always arise, and their combination continuously helps to create new and diverse contributions. The results generated by a co-creative process can be also adapted along a value chain as the user needs change over time. In the framework of living labs, co-creation emerges as a procedural concept, with different stages of development and learning. This open learning perspective of co-creation can be considered in the preparatory phase, during the co-creation process and after each phase. Hence, in the scope of continuous learning, co-creation acts as an adaptive approach to tackle the socio-transformative needs of society.

\section{FINAL NOTES}

The chapter explores the potential of co-creation for the planning of public open spaces that could be more attentive to differences, inequalities and the diversity of social ideas, needs and preferences. In times characterised by uncertainties and cultural, economic and socio-territorial diversity, co-creation can be explored as an innovation opportunity to learn and (re)think urban planning. Exploring insights, literature and experience, the discussion calls attention to the "process" contexts provided by co-creation.

Co-creation can contribute to bridge the gap between socio-spatial references and representations, bringing together ideas, needs, availability and unavailability related with socio-spatial requirements. In this way, within a given objective, co-creation can: (a) attract different disciplinary fields and reinforce inter/transdisciplinary cooperation; (b) integrate different socio-spatial representations (from stakeholders, technicians, users ...); (c) mediate opportunities, relativizing different positions and expectations towards a common decision; (d) emerge as a possibility to minimise localised problems, boosting more "feet on the ground" transformations; and (e) arise as an opportunity to create shared values within a socio-spatial community.

Co-creation implies an attitude of co-responsibility in detriment of ownership; it is collective construction, embracing different opinions and wishes, mediated and democratically managed. However, it imposes a perspective that in urban management and governance does not come easy. It requires a continuous learning process mediated by achievements and practical results, demanding a change of attitude, rather, a change of mindset in the process of creating, implementing and governing an open space from a transformative perspective that enables justice, equity, inclusion and sustainability.

Co-creation is, in fact, a challenge based on a perspective of distributive and interactive innovation, where the ownership has no relevance and the process 
of creation, in principle, is open end. A challenge that, in light of the necessary transition to a more equitable and sustainable future for cities, allows us to foresee the utopia described by Foth (2017), decentralizing from only human issues, from design and planning methods, to methods focused more on a socio-environmental approach. Performing more co-creation processes along with processes of continuing and adaptive learning might be a way to a more inclusive and responsive public space.

\section{ACKNOWLEDGEMENTS}

This work has been supported by COST Action TUI306 - CyberParks (www. cyberparks-project.eu) and by C3Places - Using ICT for Co-creation of Inclusive Public Places (www.c3places.eu.) - European Union's Horizon 2020 Research and Innovation Programme under Grant Agreement no. 693443) and FCT (Portuguese National Funding Agency for Science, Research and Technology).

\section{REFERENCES}

Bollier, David (2016). The City as Platform: How Digital Networks are Changing Urban Life and Governance. Washington, D.C.: The Aspen Institute. Available at https://www.aspeninstitute.org/ publications/the-city-as-a-platform-how-digital-networks-are-changing-urban-life-and-governance/ [Access 14 november 2018].

Cruz, M. T. (20।6). A nova economia criativa: design social e cultura da participação. In: Martinho, T. D.; Teixeira Lopes, J. \& Garcia, J. L. (Orgs.) Cultura e digital em Portugal (pp. 39-50). Porto: Edições Afrontamento, 39-50.

Ervajec, Ina Šuklje (20I7). Understanding urban public open spaces and co-creation. In: Smaniotto Costa, C.; loannidis, K. (Editors) The making of the mediated public space - Essays on emerging urban phenomena. CyberParks Project. CyberParks Project. Series Culture and Territory (2). Lisbon: Lusófona University Press, 97-107. Available at http://www.ceied.ulusofona.pt/en/serie-culture-and-territory/

Foth, M. (2017). Participation, Co-Creation, and Public Space. The Journal of Public Space, 2(4), 2I-36, DOI: 10.5204/jps.v2i4.139

Jacinto, J. A. (200I). Participação pública e comunicação política no espaço democrático municipal. Educação \& Comunicação, n. ${ }^{\circ}$ 6; 74-96. Available at http://hdl.handle.net//0400.8/244 [Access 18 september 2019].

Menezes, M. (2018). Digital in action in a neighbourhood in transformation: Notes from Mouraria in Lisbon. In: Menezes, M.; Smaniotto Costa, C. (Eds.) Neighbourhood \& City - Between digital and analogue perspectives. CyberParks Project. Series Culture and Territory (3). Lisbon: Lusófona University Press, 25-34. Available at http://www.ceied.ulusofona.pt/en/serie-culture-and-territory/

Nesti, G. (2018). Co-production for innovation: the urban living lab experience. Policy and Society, 37:3, 310-325, DOI: I0.1080/14494035.2017.1374692

Prahalad, C. K.; Ramaswamy, V. (2004). Co-Creating Unique Value with Customers. Strategy \& Leadership, Vol. 32, n. ${ }^{\circ}$ 3. Emerald Group publishing, pp. 4-9. DOI: org/ I 0.I I 08// 08785704 I 0699249

Sanders, E. B. N.; Stappers, P. J. (2008). Co-creation and the new landscapes of design. Co-Design, 4:I, 5-18, DOI: 10.1080/I57/0880701875068

Sennet, R. (2018). Building and dwelling: ethics for the city. UK: Penguin.

Smaniotto Costa, C.; Bahillo Martínez; A.; Álvarez, F. J.; Šuklje Erjavec, I.; Menezes, M. \& Pallares-Barbera, M. (20I7). Digital Tools for Capturing User's Needs on Urban Open Spaces: Drawing Lessons from 
Cyberparks Project. In: Certomà, C.; Dyer, M., Pocatilu, L.; Rizzi, F. (Editors) Citizen Empowerment and Innovation in the Data-Rich City. Springer International Publishing, PP. I77-194. DOI: 10.1007/ 978-3-319-47904-0

Smaniotto Costa, C.; Šuklje Erjavec, I.; Kenna, T.; de Lange, M.; loannidis, K.; Maksymiuk, G. \& de Waal, M. (Eds.) (2019) CyberParks - The Interface Between People, Places and Technology - New Approaches and Perspectives. Springer, Series: Information Systems and Applications LNCS. DOI: 10.1007/ 978-3-030-134I7-4. ISBN 978-3-030-13416-7. Available at https://link.springer.com/book/10.1007\% 2F978-3-030-134I7-4

Voorberg, W. H.; Bekkers, V. J. J. M. \& Tummers, L. G. (2015). A Systematic Review of Co-Creation and Co-Production: Embarking on the social innovation journey. Public Management Review, 17:9, I333-1357, DOI: $10.1080 / 147 \mid 9037.2014 .930505$

Voorberg, W. H.; Bekkers, V. J. J. M.; Timeus, Krista; Tonurist, Piret \& Lars Tummers (2017). Changing public service delivery: learning in co-creation, Policy and Society, 36:2, I78-194, DOI: 10.1080/ |4494035.20|7.|3237| | 